\title{
Novel use of radio-location for a ground investigation at Pen Park Hole, Bristol, United Kingdom
}

\author{
A R Farrant ${ }^{1}$ and G J Mullan ${ }^{2}$ \\ ${ }^{1}$ British Geological Survey, Keyworth, Nottingham, NG12 5GG, Great Britain. \\ (e-mail: arf@bgs.ac.uk) \\ ${ }^{2} 38$ Delvin Road, Westbury-on-Trym, Bristol BS10 5EJ
}

$\begin{array}{ll}\text { Number of words } & 4060 \\ \text { Number of references } & 15 \\ \text { Number of tables } & 2 \\ \text { Number of figures } & 12\end{array}$

\begin{abstract}
Pen Park Hole is currently the UK's only known hydrothermal cave system. Situated under a large housing estate in north Bristol, it contains one of Britain's largest natural underground cavities, the roof of which is only a few metres below the surface.
\end{abstract}

Discovered in 1669 , the cave has had a long history of investigation, including being the object of the world's first published cave survey in 1683. In 2006, a telecommunication company submitted a planning proposal to erect a transmitter close to the site. Given the sensitive nature of the cave and potential uncertainties in the accuracy of a more recent cave survey, Bristol City Council planners required a better fix on the location of the cave.

The urban surroundings prevented traditional geophysical techniques being used, and a ground penetrating radar survey failed due to thick residual clay soils over the site. Instead, radiolocation was employed to check on the accuracy of the existing cave survey, allowing it to be georectified in relation to the surface. The confirmed reliability of the survey, coupled with an assessment of the cave geomorphology, has enabled the planners to assess the potential for the proposed mast works to intersect the cave or any associated undiscovered voids.

Pen Park Hole is a large cave system located in the Southmead housing estate on the north side of Bristol [ST 5852 7921] (Fig. 1). It occurs in a steeply-dipping ridge of Carboniferous Limestone that has been partly buried by Triassic and basal Jurassic strata. Here the Carboniferous Clifton Down Limestone Formation dips at $50^{\circ}$ to the north-west along the northern side of the Kingsweston Anticline. The rock is cut by numerous minor shear planes related to bedding plane slip, and shows evidence of lead-zinc mineralization. The entrance to the cave occurs just below the Triassic unconformity, where overlying flat or gently-dipping Penarth Group sedimentary rocks have been stripped off the Carboniferous Limestone ridge. Westbury Formation mudstones occur in the immediate vicinity of the cave entrance, and rest unconformably on the Clifton Down Limestone. Overlying the Westbury Formation is the Blue Lias Formation (Wilmcote Limestone and Saltford Shale members), which forms a small ridge $400 \mathrm{~m}$ to the south of the cave entrance.

The present entrance to the cave is via a short mined shaft (Fig. 2a-c). This enters a strike-aligned, fault-guided passage, which doubles back on itself to emerge on a 
ledge about two-thirds of the way up one of the largest cave chambers in Britain. The void measures approximately $34 \mathrm{~m}$ by $30 \mathrm{~m}$ and at its maximum is estimated to be 50 $\mathrm{m}$ high. The chamber is inclined parallel with the dip, here typically $50^{\circ}$. The entrance passage enters the side of this chamber about $40 \mathrm{~m}$ above the floor. Above this point the main chamber rises to a narrow rift just a few metres below the surface; this was the original entrance to the cave. The floor of the chamber is covered by thick mud and breakdown, and a large lake whose water-level fluctuates by at least $27 \mathrm{~m}$ and possibly as much as $35 \mathrm{~m}$. Two short passages, East Passage and West Passage, lead off along strike on opposite sides of the chamber.

Many of the original cave walls, where still intact, are covered by a layer of crystalline dog-tooth calcite crystals up to $10 \mathrm{~cm}$ thick, with minor lead and copper mineralization. The tree-like geometry of the cave, the mineralization and several good examples of condensation cupolas indicate the cave was formed by ascending geothermal waters, rather than by descending groundwater, as is considered typical of most normal cave systems in the UK. Examination of the cave geomorphology suggests geothermal water rose from depth up a series of bedding planes and shear planes caused by bedding plane slip to emerge on the surface. Consideration of the regional mineralization and the cave's location just beneath the Triassic unconformity suggests the system was probably active in Late Triassic times (Mullan 1993).

Modern-day hot springs occur elsewhere in the Bristol area. The Hotwells and Jacob's Well springs are situated on the north side of the River Avon in Clifton, $6.8 \mathrm{~km}$ to the south, and the famous Bath hot springs occur $22 \mathrm{~km}$ to the south-east.

\section{Early investigations}

The cave is of significant historic interest. It was discovered by quarrying (not by lead miners as is commonly assumed) in or shortly before 1669, and was of considered of sufficient interest for King Charles II to be informed. It was first descended by Captain Samuel Sturmy on $2^{\text {nd }}$ July 1669 at the request of the King. Sturmy's account of the descent has been published by Southwell (1683), Catcott (1792) and others. The second exploration of the cave was by Captain Greenville Collins of the Survey Yacht Merlin and his crew on 18th and $19^{\text {th }}$ September 1682. They surveyed the cave, and the survey was published the following year by the Royal Society (Southwell 1683). This is thought to be the first recorded published survey of a natural cave (Shaw 1979).

Apart from a visit in 1760 by Alexander Catcott, who was accompanied by three coal miners from nearby Kingswood, and miners investigating the cave for lead ore in around 1769 , few recorded visits were made to the cave until 1775 . On the $17^{\text {th }}$ March that year, the Reverend Newnam fell to his death when the branch he was holding whilst trying to plumb the depth of the main shaft, broke.

This event rekindled interest in the site and subsequently the cave was resurveyed between 1775 and 1776 by Mr. William White, with the assistance of George Catcott, Alexander's brother. White drew a plan of the surface features and two cross-sections of the cave. The survey is shown in Fig. 3, and is reproduced from a manuscript (MSS B10158) held in the Bristol Records Office. It is a copy of George Catcott's description, with additional material by an unknown author, but possibly Thomas Cole; the handwriting is neither Catcott's nor White's.

On White's 1779 survey, the original entrance, that into which the Rev. Newnam fell to his death, is the main rift marked HIK, which lies at the upper end of the Main 
Chamber and is currently blocked. F and G mark the location of a series of alternative entrances to his 'West Passage', which lies along the line of, but to the west of, the main rift. This passage is no longer accessible and has been lost, but probably exists above and up-dip from Upper West Passage, and lies very close to the surface. An attempt to climb into this postulated high-level passage in 1992 was aborted due to the danger of loose rock. E marks another small hole, now no longer visible, that lies very close to Pen Park Road. The present entrance is marked L. It was originally a vertical shaft along the same rift and was enlarged by miners searching for lead ore. A version of this survey was published by Catcott in 1792 . The cave was closed by the landowner in the latter part of the $19^{\text {th }}$ century on safety grounds.

\section{Reopening of the cave}

The cave had been largely ignored, but not forgotten until the 1950s when the development of the Southmead housing estate required a more detailed investigation of the site to enable building works to be carried out.

In order to relocate the cave, a geo-resitivity survey was undertaken by Prof. L.S. Palmer on behalf of the City Council in 1956. This successfully located the cave, and the eastern mined entrance was reopened by a consortium of local caving clubs in January 1957. During the following three years the cave was surveyed by Prof. E K Tratman and members of the University of Bristol Spelaeological Society, and the cave geomorphology and biology were studied by the Cave Research Group. The results of these studies, the survey and the geophysical survey were published in a report by the Cave Research Group (Tratman 1963).

The cave was closed again in 1961 by Bristol City Council. In 1992, as part of a landscaping project, permission was granted by the Council to reopen the cave. This was done by the same consortium of local caving clubs on $7^{\text {th }}$ February 1992 and an access agreement drawn up. As a result of the improved access, the cave was reexamined, the lake at the bottom of the cave dived and Upper East Passage explored. A reassessment of the early history of the cave was published by Mullan (1993); this included an updated version of the survey, corrected for minor drafting errors and with the addition information on Upper East Passage and the submerged extension to the lake. This is the survey reproduced in Fig. 2. However, because the original 1950s survey stations in the cave were not recorded, nor were their corresponding surface locations, there is no objective way of testing the accuracy of the published survey without further survey work.

\section{Former site investigation work.}

Because of the cave's long history, its proximity to the surface and its location in the centre of an urban area, it has been the subject of a series of site investigations. The most extensive work was Palmers' resistivity survey in 1956 (Fig. 4). Palmer claimed the survey predicted the location of the mined entrance sufficiently accurately for it to be reopened in 1957. However, Mullan (1992) suggests that Palmer identified the present entrance more from White's 1779 plan than from his resistivity data. The survey certainly appears to have over-estimated the size and extent of the Main Chamber. Furthermore, the resolution of the survey was not sufficient to pick up the smaller Upper West Passage or White's high level West Passage.

Nine shallow boreholes (Table 1) were drilled in 1980 as part of the site investigation for a housing development on Briarside Road to the north of Pen Park Hole. None of these penetrated any cavities in the Carboniferous Limestone. This is perhaps not 
surprising given the limited number of boreholes sunk. Nearly all the boreholes were sited to the west of the known cave, where the cave descends steeply down-dip.

\section{The planning application}

In 2006, Bristol City Council received a planning application from a telecommunications company to site a Third Generation $12.5 \mathrm{~m}$-high telecommunication mast with a 3.3 m-deep concrete foundation block on Pen Park Road at the western corner of the public park which overlies the cave [ST 5845 7919]. The planning authority, aware that the cave existed, gave consent to the company to erect the mast, with the condition that a geological investigation of the area should be carried out prior to work commencing. The exact wording of the condition was as follows:

'No development shall take place until a full geological investigation of the site and the surrounding area has been undertaken and a report setting out the findings, any preparatory works necessary and the design of the foundation has been submitted to and approved in writing by the local planning authority and these works shall be carried out as approved.'

The applicants produced a draft brief for this investigation, which involved drilling down to $30 \mathrm{~m}$ and concreting up any cavities encountered. Clearly this would have had significant negative impacts on the cave system if it were to be encountered, and possibly required large amounts of grout. Following the submission of the application, the planning authority asked the company to commission a more detailed geological report from the British Geological Survey and to comment on the proposed site investigation.

An initial desk study using historical documents, geological data held at the National Geological Data Centre at Keyworth, and the available cave surveys (Rudder 1779; Tratman 1963; Mullan 1993) indicated that the site of the proposed telecommunication mast was very close to the upper end of White's 'West Passage', and to the site of a possible former cave entrance (E) shown on his survey. Consideration of the cave geomorphology also suggested that as yet undiscovered extensions could occur. The ascent of the thermal waters was guided principally by bedding planes and the bedding plane slip shear zones. Geothermal hypogene caves of this type typically display an upward branching form near the surface (Ford \& Williams 1989), and this is well displayed in Pen Park Hole. All the known passages branching off the main conduit occur along strike either side of the Main Chamber. It was considered quite likely that further karstic voids might exist along strike from the known cave.

To determine whether a cavity exists beneath the proposed mast site, the telecommunications company requisitioned a geophysical survey of the site. A ground penetrating radar survey was undertaken by Terradat Ltd using a Pulse Echo 1000 radar system with a $100 \mathrm{MHz}$ antenna. Three lines, one along Pen Park Road and two parallel lines linking the mast with the presumed site of the original entrance and the current entrance were surveyed, with disappointing results (Terradat 2006). Thick conductive residual clay soils derived from the overlying Penarth Group mudstones prevented decent radar signal penetration into the underlying Carboniferous Limestone. Because of this lack of signal penetration, it proved impossible to determine whether there were any karstic voids beneath the site. 
An alternative approach was needed. However, the detection of cavities in an urban environment is often difficult due to buried networks, reworked soils, geophysical noise and other factors. Although methodologies to overcome this using integration of complementary geophysical methods such as borehole analysis, microgravimetry, and ground penetrating radar have been devised (Thierry et al., 2005), for this application this approach was too costly.

Rather than commission a potentially fruitless and expensive resistivity or microgravity survey, a radio-location exercise was undertaken to determine the accuracy of the existing cave survey.

\section{Radiolocation technique}

The use of the Very Low Frequency transmissions to determine position and depth of a cave passage is a well established technique used by cavers to determine the accuracy of cave surveys in relation to the surface. It has also been used to pinpoint potential new cave entrances into known cave systems, and to locate sites for water abstraction from known underground streamways in karst areas. A similar radiolocation technique has been in the mining industry, where signals picked up from body-worn transmitters can allow prone or unconscious miners to be located.

In this case, the technique had the advantage of being relatively quick and costeffective. The radiolocation methodology and theory have been outlined in detail by Glover 1976; Gibson 1996, 1998, 2001, 2002 and by France 2001.

The radio-location technique employs an inductive radio communication system operating in a non-radiating near-field mode at $87.5 \mathrm{kHz}$ SSB using a single-sideband suppressed carrier. It works on the same principle as a transformer (Figs. 5 and 6).

The transmitter passes current through one coil, which generates a magnetic field. This field induces a current in a second coil held some distance away (Fig. 7). A receiver amplifies this extremely small current and is then used to create sound in a set of headphones. By putting a receiver and a transmitter in the same box, two-way speech communication can be conducted through rock strata up to about 300 m thick. By use of a short tone pulse from the underground transmitter it is possible to determine Ground Zero, the position at surface vertically above the transmitter. The transmitter/receiver is housed in a metal waterproof box complete with telephone handset and a 12 volt battery. A $1 \mathrm{~m}$-diameter ribbon loop aerial is also included. The surface equipment also includes a collapsible plastic frame for holding the loop aerial in a rigid position, this being needed during the location procedure.

It is possible to determine the surface location of a cave passage and its depth with a reasonable degree of accuracy depending on the depth of the passage. At depths of around $20 \mathrm{~m}$ location, typical accuracies are in the region of 1 to $2 \mathrm{~m}$ diameter. At 200 $\mathrm{m}$ it will be in the region of $20 \mathrm{~m}$. However, in ideal conditions with a levelled antenna an experienced operator can achieve an x-y accuracy at ground level of $1 \mathrm{~m}$ for a $50 \mathrm{~m}$ depth $(2 \%)$ and a depth accuracy of perhaps 5\%. Errors increase with the angle of tilt of the antenna; a $5^{\circ}$ tilt induces additional errors of $3 \%$ (Gibson 2002). If the surface terrain is uneven this must be taken into account or further errors will result. However, the terrain around Pen Park Hole is flat or very gently sloping, so no terrain corrections were required.

A receiver loop on the surface placed in a field generated by an underground transmitter will receive a maximum signal when the field lines cut the receiver loop at right-angles (Fig. 8). Figure 9 shows the arrangement within a cave. In Figure 10 a 
plan view of the field pattern is shown. In this arrangement, a vertical receiver loop placed at other angles (positions B \& D) will receive lower signals until a null signal is found when the loop is parallel to the field (position C). The maximum signal occurs at position A.

The plane of the vertical receiver loop now forms a line, which is staked out using marker posts by the surface team. Another null line can be established by moving sideways at right-angles to the first line for a short distance; where the two line cross is the point directly above the underground transmitter loop - Ground Zero. As a check other null lines can be established, and the exact location determined from their intersections.

Once the approximate location of Ground Zero has been established, its location can be verified and refined by spinning a vertical loop and checking that the null point is symmetrical. For maximum accuracy the underground loop must be as level as possible. For this reason, the underground location needs to be chosen where there is sufficient space to operate the coil in a horizontal position. Given an accurate Ground Zero location, it is possible to calculate the depth. Fig. 11 shows details of the measurements required.

By moving away from epicentre along one of the lines previously set up with the receiver held horizontally, a null signal will be obtained at a point when the field is parallel to the ground surface. A clinometer or spirit level is normally attached to the receiver to ensure it is being held horizontally. At this point the depth can be calculated from the equation:-

Depth $=\mathrm{L} / \sqrt{ } 2$

where $\mathrm{D}$ is the depth and $\mathrm{L}$ is the horizontal distance to the null point, and the null angle $\alpha$ is zero i.e. loop held horizontally. At any other null angle $(\alpha)$ the depth may be calculated from the equation.

Depth $=2 \mathrm{~L} /\left(\sqrt{ }\left(9 \tan ^{2} \alpha+8\right)-3 \tan \alpha\right)$

The depth can also be calculated once Ground Zero is fixed by measuring the field strength using calibrated equipment, as the field strength decays as the inverse cube of distance.

However, in many circumstances this method does not give very accurate results because the signal is either weak at this distance or the field lines become too distorted to be relied on. This is especially true at relatively high frequencies. To get a good accuracy for depth it is a more common practice to take the distance at which alpha is 45 degrees, for which the depth is then about 1.78 times the horizontal offset.

The radio-location exercise was undertaken using equipment on loan from the Mendip Rescue Organisation, and manpower from the University of Bristol Spelaeological Society. One four-person team went underground and transmitted from three predetermined locations using the published cave survey. These were on the West Platform, at the top of the $20 \mathrm{~m}$ pitch in the Main Chamber and in the First Chamber. The corresponding surface location (Ground Zero) above each point was fixed by an operator on the surface using the radiolocation technique and accurately located both by using a hand held Garmin Global Positioning System (GPS), and by measuring from known fixed points on the surface using a tape and compass bearings. These locations were then located on an Ordnance Survey 1:10 000 scale base map and on a geo-rectified aerial photograph. From these, the National Grid co-ordinates were 
obtained. The coordinates of the present cave entrance were also located accurately using GPS and by measuring to the fixed points.

\section{The results of the radio-location}

The co-ordinates of the Ground Zero points derived from GPS, compass bearings and aerial photographs are shown on Table 2. Both the points on the West Platform and at the top of the $20 \mathrm{~m}$ pitch in the Main Chamber proved to be quite accurate, and within about a metre of the predicted position from the cave survey. However, the point in the First Chamber proved to be located about $8 \mathrm{~m}$ to the north-east. The reason for this is not immediately apparent. It might be an error generated during the radiolocation exercise caused by a tilted antenna, inaccurate null line sighting (the surface location was in a thick hedge), or a drafting error on the original survey. The close correlation between the GPS coordinates and those obtained from the compass readings implies that the uncertainty on points 2 and especially 3 is a combination of possible survey issues and determining visual sightings along the null line through a thick hedge in poor weather conditions.

These new radio-located grid references were used to georectify the cave survey. Several geo-rectification methods were used. Rubber sheeting using ERDAS Imagine software proved inadequate due to the limited number of radio-located control points available. Simple rotations using the more accurate West Platform and Entrance fixed points proved more successful (Fig. 12).

Although parts of the cave survey have shifted position, it is clear that the cave survey is substantially accurate. The relative position of the western end of the cave, nearest to the proposed telecommunication mast, has not been changed by more than a few metres. It lies approximately $7 \mathrm{~m}$ from and $8 \mathrm{~m}$ below the proposed mast location.

Although this exercise demonstrates that the main cave void lies to the east of the proposed mast location, evidence from White's 1779 survey and predictions based upon the cave geomorphology indicate the distinct possibility of further unknown and unsurveyed karstic voids in the vicinity of the proposed mast. Based on this information and given the sensitive nature of the site, the telecommunications company submitted a revised planning application to relocate the mast $30 \mathrm{~m}$ to the south-east.

\section{Conclusions}

Radiolocation techniques can be used to verify the accuracy of an existing cave or mine survey that can be used as an aid to site investigation work. This method, coupled with a detailed desk study and knowledge of cave geomorphology, enabled a detailed assessment of the risk posed to a proposed telecommunication mast from near-surface underground voids. This technique was used here because conventional ground penetrating radar techniques had failed. This avoided the need for additional costly and possibly inconclusive geophysical surveys. However, for a more accurate geo-rectification of the survey, many more radio-located points would be required, using a lower frequency, which would have required more time and expense.

Based on this information, the proposed mast was moved to a different location. This prevented damage to a unique cave system and achieved a positive outcome for the telecommunications company, the planning authority and the local caving community. The telecommunication company avoided a potentially embarrassing and costly incident and were able to relocate their mast without requiring an invasive site investigation or further expensive geophysical surveys. 
Acknowledgements. Thanks go the Mendip Rescue Organisation, particularly Brian Prewer for the loan of the radiolocation equipment. Brian Prewer, Chris Binding, and members of the University of Bristol Speleological Society including Gina Moseley, Linda Wilson, Hannah Sargent and Marc Luetscher volunteered their time to do the radiolocation exercise. Thanks also go to Daniel Stone and the late Jon Brett of Bristol City Council and Peter Cherry for allowing this work to be done. The telecommunication company kindly provided a small donation to the Mendip Rescue Organisation and the University of Bristol Spelaeological Society for their services. Tony Cooper and David Gibson kindly read through the manuscript and provided useful comments. Bob Mackin drew up the original diagrams upon which Figs. 6-11 are based. The survey of Pen Park Hole is used with the permission of the University of Bristol Spelaeological Society Proceedings.

\section{References}

Catcott, G. S. 1792. A Descriptive Account of a Descent made into Penpark Hole. J. Rudhall. Bristol.

Ford, D. C. and Williams, P. W. 1989. Karst Geomorphology and Hydrology. Unwin Hyman. London.

France, S. 2001. Cave Surveying by Radio-Location - 2. Cave Radio \& Electronics Group Journal, 44, 21-23.

Gibson, D. 1996. How Accurate is Radio-location? Cave \& Karst Science, 23, 77-80

Gibson, D. 1998. Radiolocation Errors Arising from a Tilted Loop. Compass Points, 21, 18-20.

Gibson, D. 2001. Cave Surveying by Radio-Location - 1. Cave Radio \& Electronics Group Journal, 43, 24-26.

Gibson, D. 2002. Radiolocation for cave Surveying. World Wide Web Address: http://caves.org.uk/radio/radioloc for cave.html

Glover, R. R. 1976. Cave surveying by electromagnetic induction. In: Ellis, B (ed) Surveying Caves. British Cave Research Association. Bridgewater.

Mullan, G. J. 1992. Resistivity Work - An Historical Perspective. Newsletter of the William Pengelly Cave Studies Trust Limited. 64, 1-2.

Mullan, G. J. 1993. Pen Park Hole, Bristol: A reassessment. University of Bristol Spelaeological Society Proceedings, 19, 291-311.

Rudder, S. 1779. A New History of Gloucestershire. Cirencester.

Shaw, T. R. 1979. A history of Cave Science. A. Oldham. Crymych.

Southwell, R. 1683. A Description of Pen-Park-Hole in Glocestershire. Philisophical Transactions of the Royal Society, 13, 2-6.

Terradat, 2006. Geophyscal Survey Report 1833. Unpublished report for Needham Haddrell.

Thierry, P., Debeblia, N. \& Bitri, A. 2005. Geophysical and geological characterisation of karst hazards in urban environments: applications to Orléans (France). Bulletin of Engineering Geology and the Environment, 64, 139-150.

Tratman, E.K. 1963. Reports on the Investigation of Pen Park Hole, Bristol. Cave Research Group of Great Britain Publication, 12. 


\section{Figures}

Fig. 1. Location of Pen Park Hole in north Bristol, with the 1:50 000 scale digital bedrock geology and borehole locations shown.

Fig. 2. $\quad$ (a) Plan of Pen Park Hole with radiolocation points.

(b) East-west elevation of Pen Park Hole.

(c) North-south elevation of Pen Park Hole (adapted from Mullan 1993).

Fig. 3. White's 1779 survey of the surface of Pen Park Hole. KIH is the original entrance to the cave, $\mathrm{L}$ is the present mined entrance. $\mathrm{G}$ and $\mathrm{F}$ are additional entrances to 'West Passage', E is another smaller cave entrance. A marks small hollows. D is approximately the location of the proposed telecommunication mast on Pen Park Road. Adapted from Tratman 1963.

Fig. 4. Plan view of the 1956 resistivity survey (thick black line) by Prof. L. Palmer with the modern cave survey (shaded) superimposed (Mullan, 1993). Adapted from Tratman, 1963.

Fig. 5. Magnetic flux path generated by coils coupled with a core

Fig. 6. Magnetic flux path generated by coils coupled without a core

Fig. 7. The cut apple-shaped field pattern associated with the horizontal underground loop aerial.

Fig. 8. Receiving antenna positions aligned for maximum signal. These are shown as the rectangles cutting the field lines at $90^{\circ}$.

Fig. 9. Arrangement of field paths from a transmitter underground and the receiving coil on the surface.

Fig. 10. Plan view of the field on the surface above the transmitter. Receiver positions A-D indicate maximum signal strength (A) to null signal strength $(\mathrm{C})$, which can be used to mark out a null line. Intersections of these null lines mark the Ground Zero point.

Fig. 11. Determination of depth from radiolocation measurements. $\mathrm{L}$ is distance from Ground Zero and $\alpha$ is the field angle.

Fig. 12. Plan of Pen Park Hole relative to the surface using the radio-located point on the West Balcony and the Entrance to fix the survey. Black circles mark the radiolocation points. The postulated location of White's 'West Passage' is shown. 


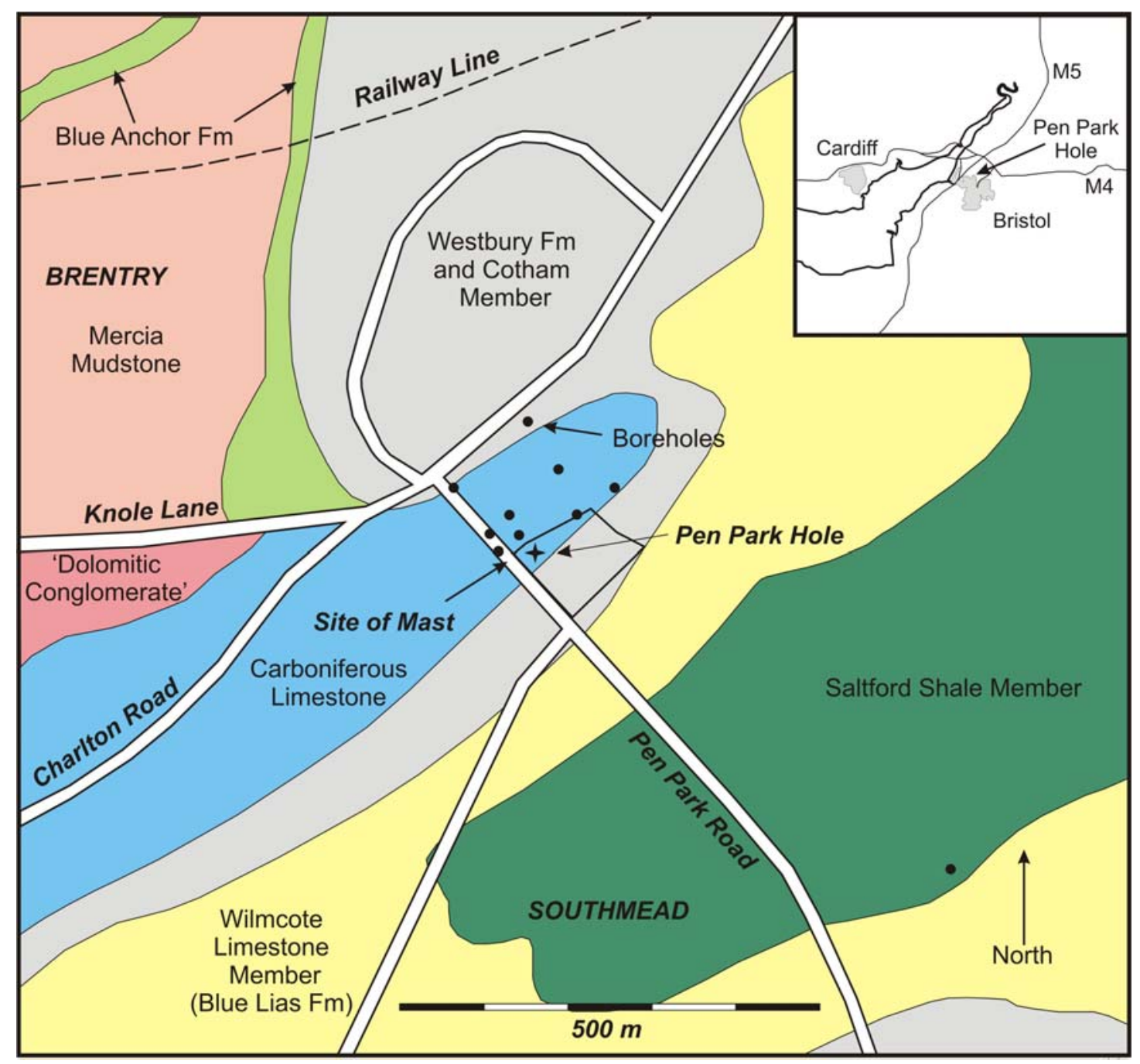

Fig. 1. Location of Pen Park Hole in north Bristol, with the 1:50 000 scale digital bedrock geology and borehole locations shown. 


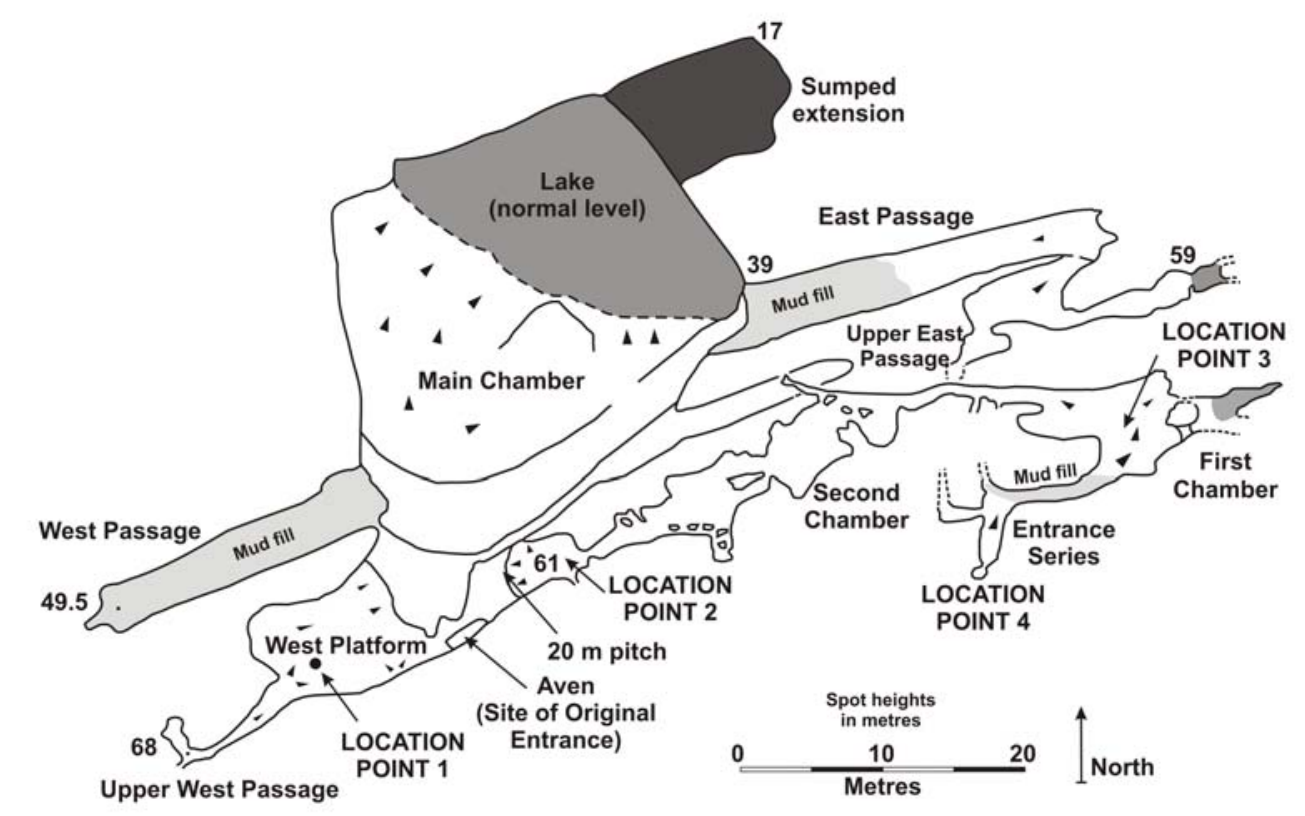

PEN PARK HOLE PLAN

From: G. J Mullan 1993. University of Bristol Spelaeological Society Proceedings 19, 291-311

Fig. 2. (a) Plan of Pen Park Hole with radiolocation points.

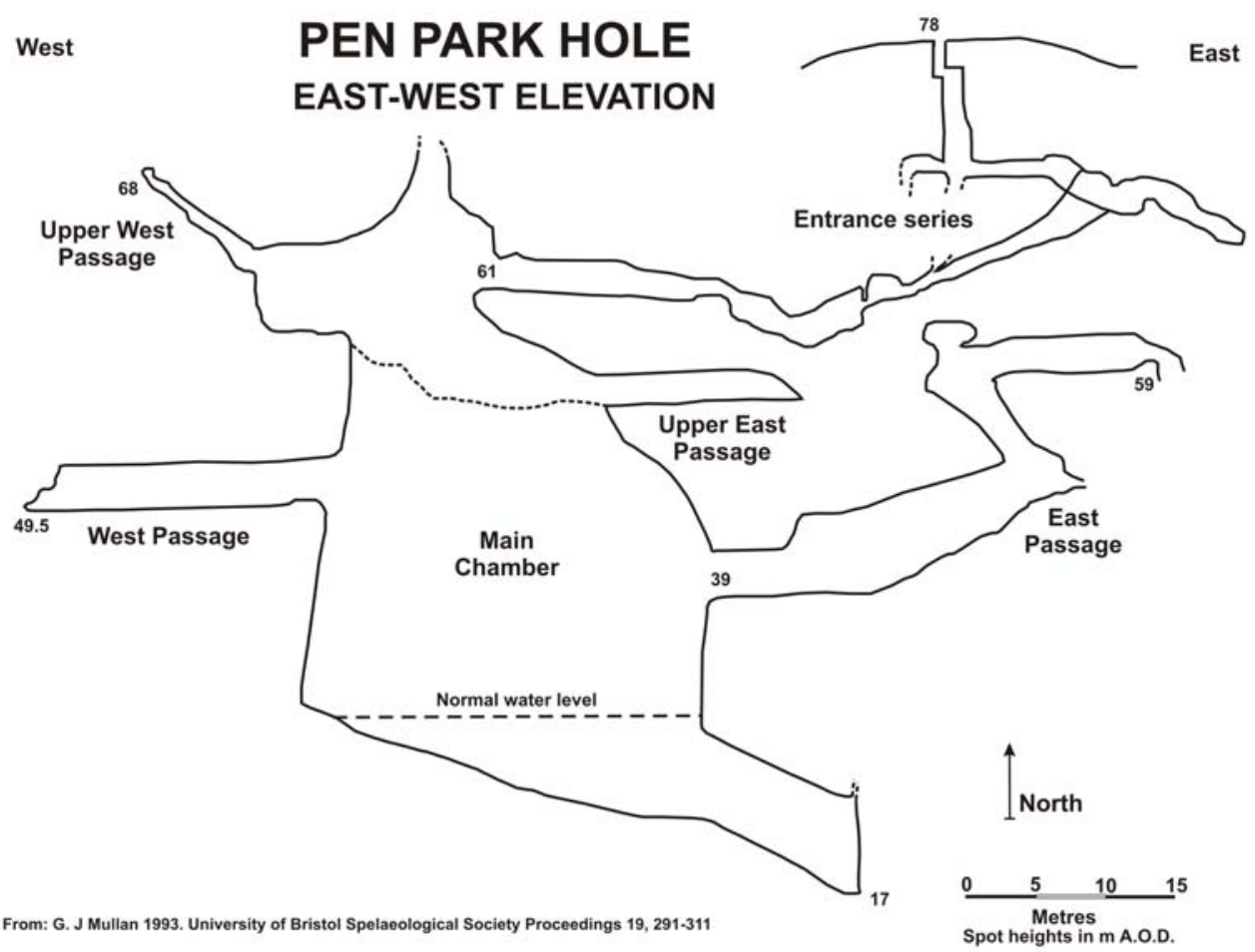

(b). East-west elevation of Pen Park Hole. 


\section{PEN PARK HOLE NORTH-SOUTH ELEVATION}

North

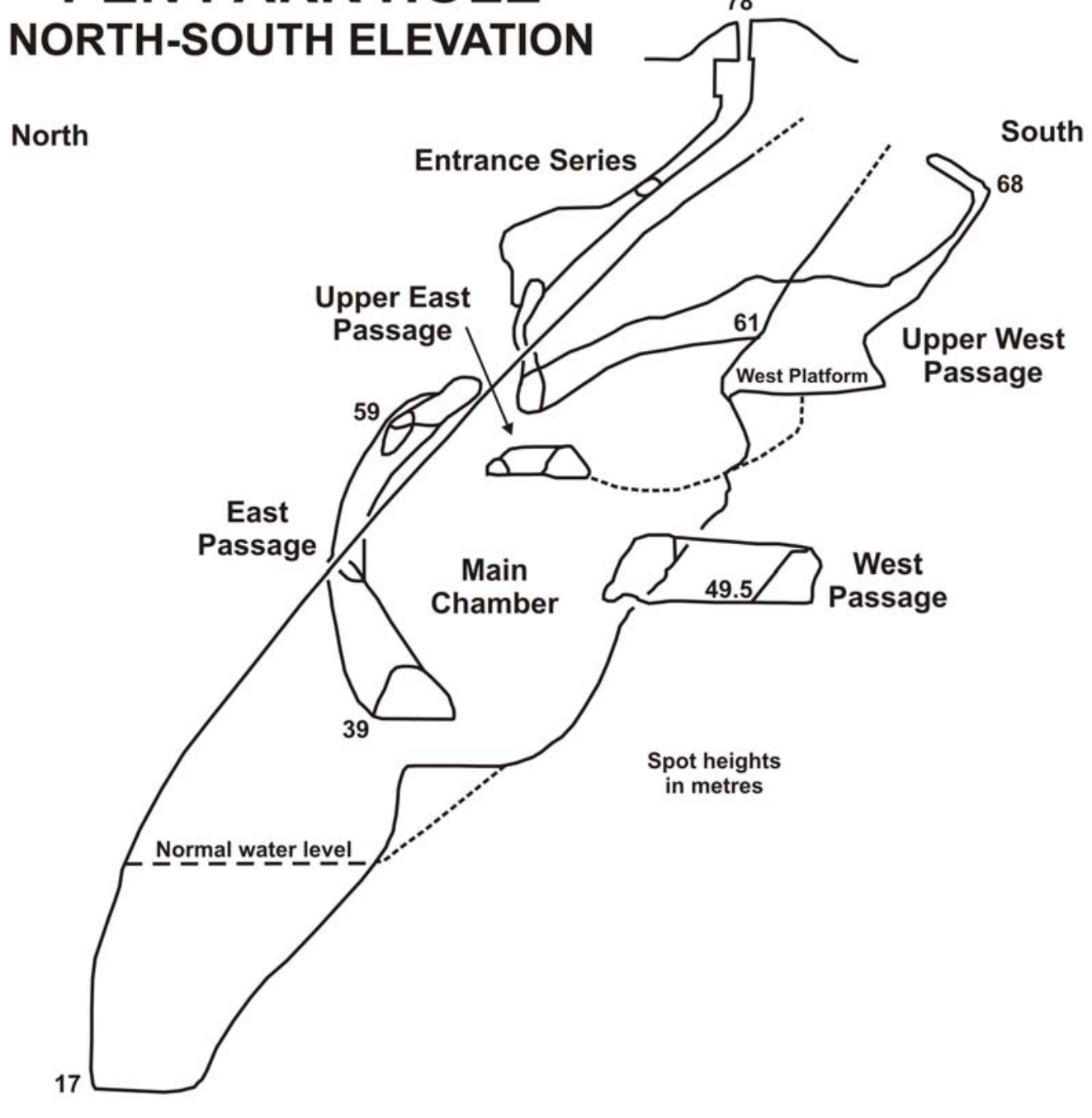

From: G. J Mullan 1993. University of Bristol Spelaeological Society Proceedings 19, 291-311

(c). North-south elevation of Pen Park Hole (adapted from Mullan, 1993). 


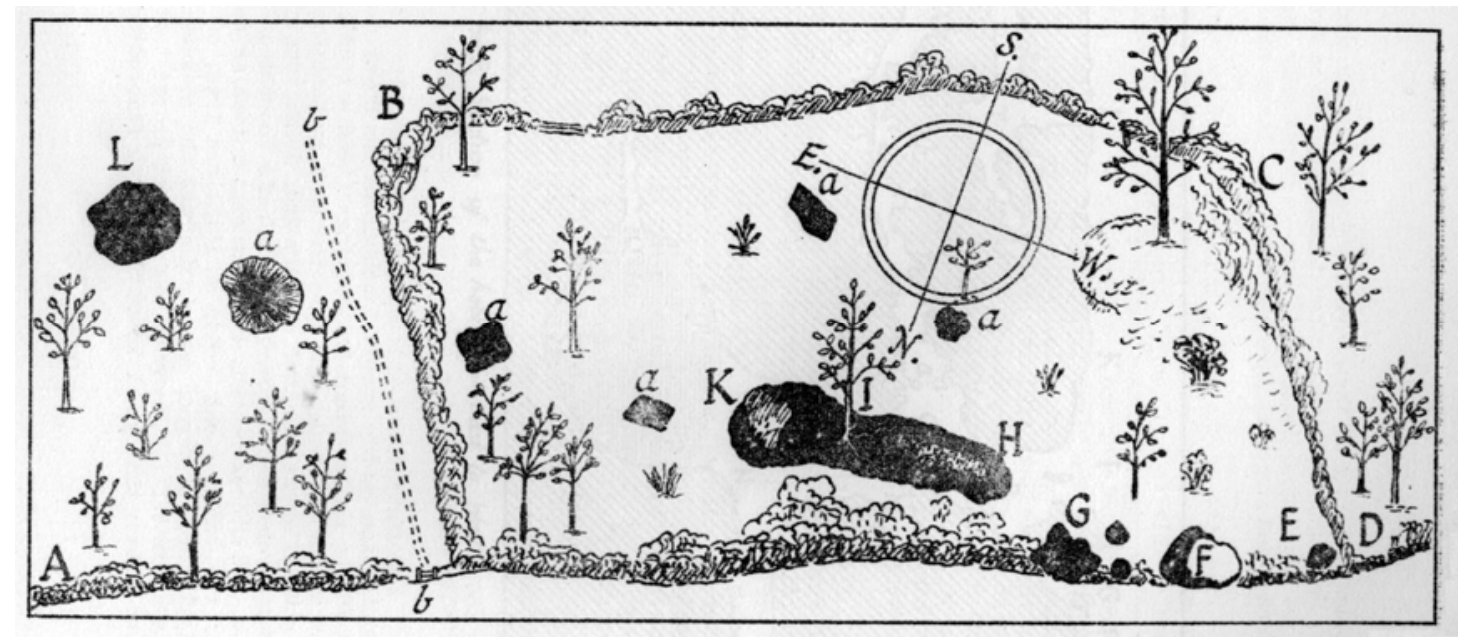

Fig. 3. White's 1779 survey of the surface of Pen Park Hole. KIH is the original entrance to the cave, $\mathrm{L}$ is the present mined entrance. $\mathrm{G}$ and $\mathrm{F}$ are additional entrances to 'West Passage', $\mathrm{E}$ is another smaller cave entrance. A marks small hollows. D is approximately the location of the proposed telecommunication mast on Pen Park Road. From Tratman, 1963. 


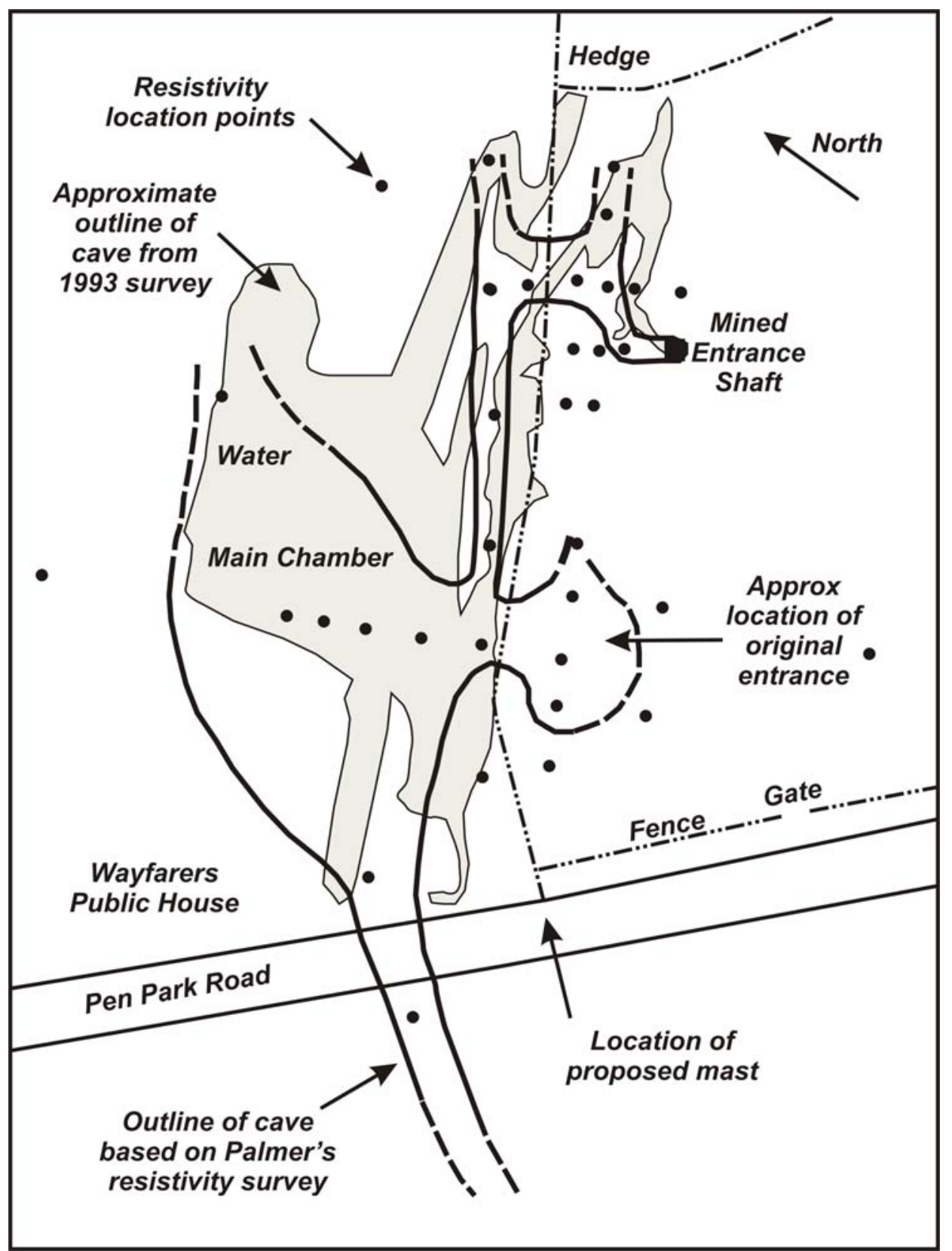

Fig. 4. Plan view of the 1956 resistivity survey (thick black line) by Prof. L. Palmer with the modern cave survey (shaded) superimposed (Mullan, 1993). Adapted from Tratman, 1963.

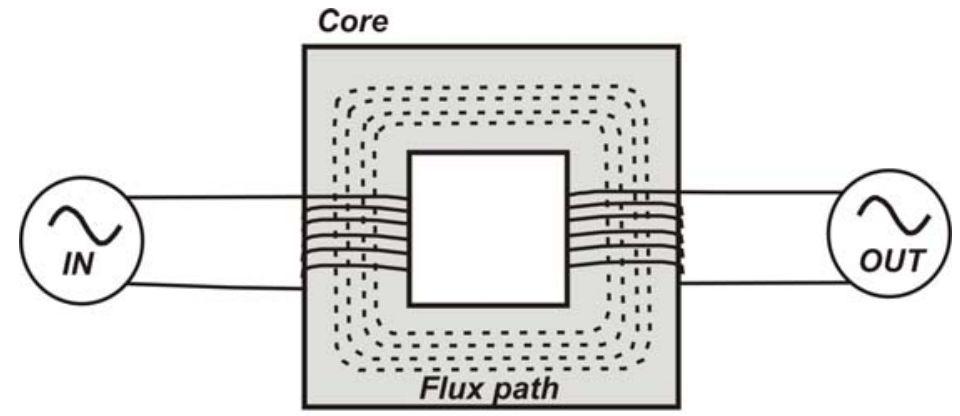

Coils coupled with a core 
Fig. 5. Magnetic flux path generated by coils coupled with a core

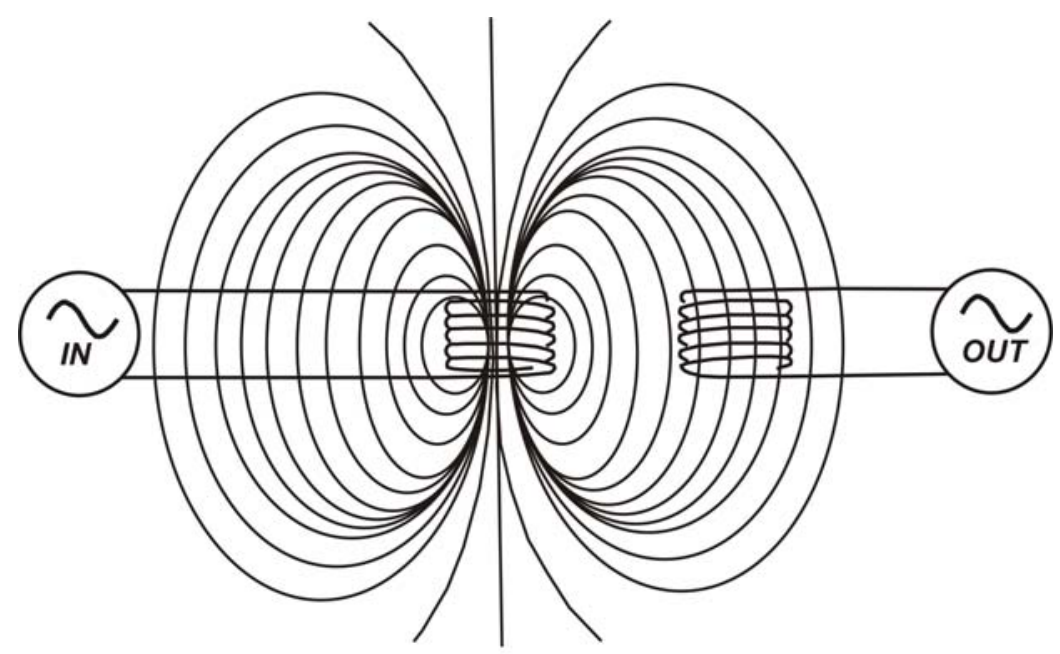

Coils coupled without a core

Fig. 6. Magnetic flux path generated by coils coupled without a core

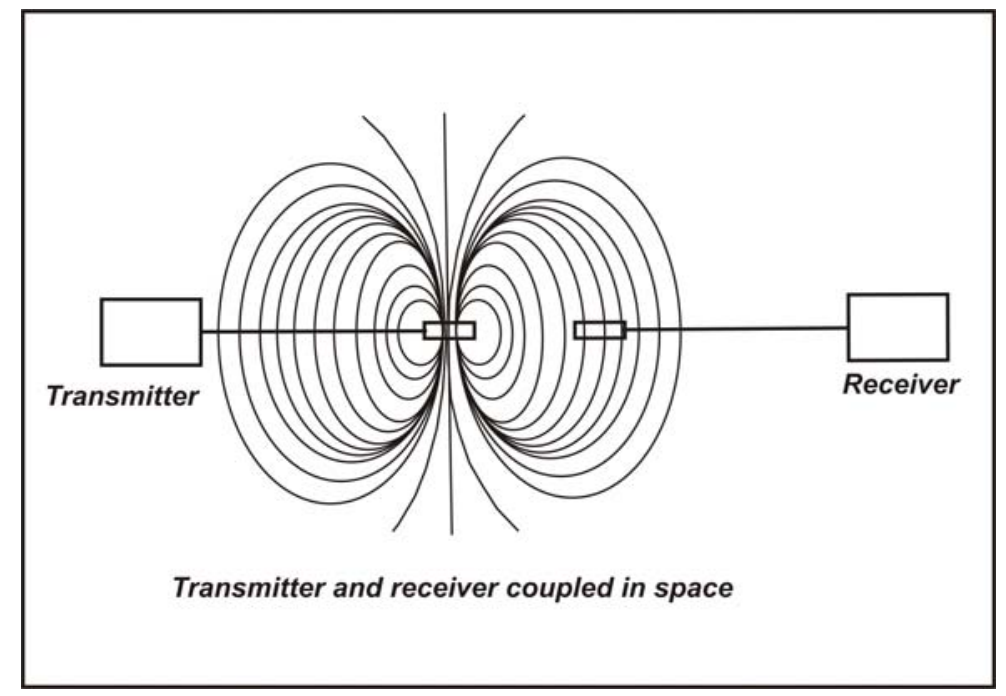

Fig. 7. The cut apple-shaped field pattern associated with the horizontal underground loop aerial. 


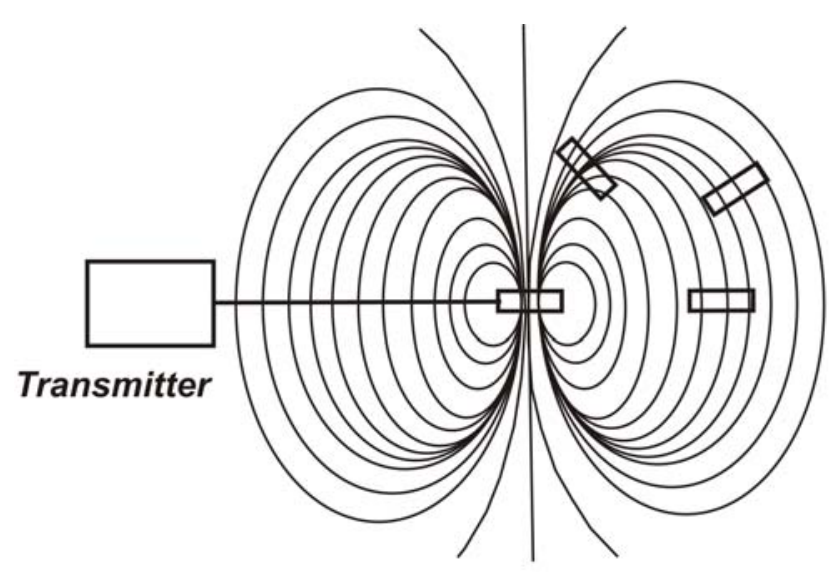

Receiving coil aligned for maximum signal

Fig. 8. Receiving antenna positions aligned for maximum signal. These are shown as the rectangles cutting the field lines at $90^{\circ}$.

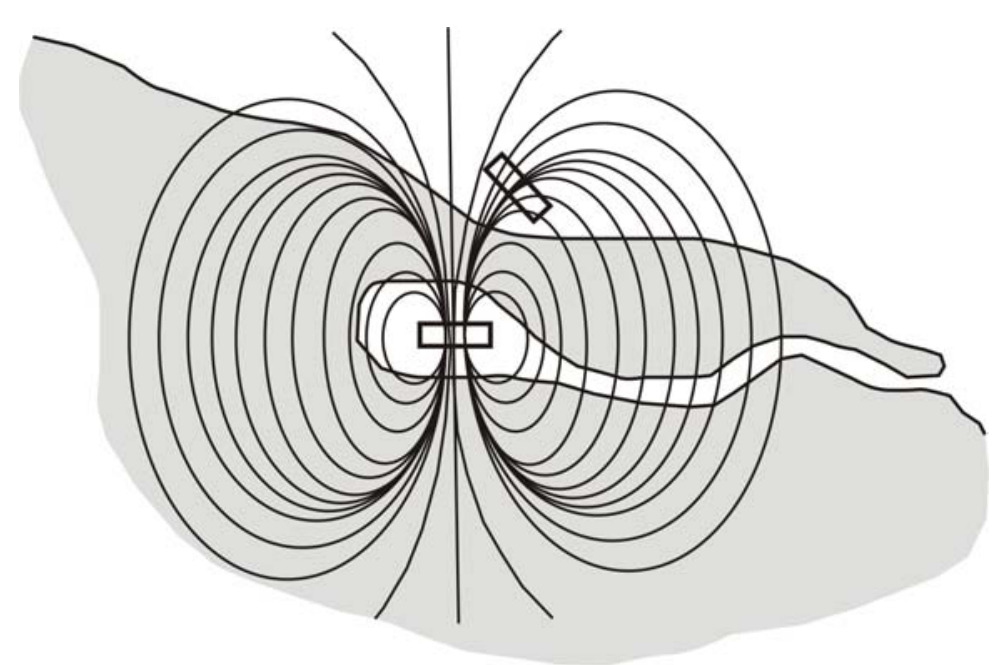

Transmitter in a cave

Fig. 9. Arrangement of field paths from a transmitter underground and the receiving coil on the surface. 


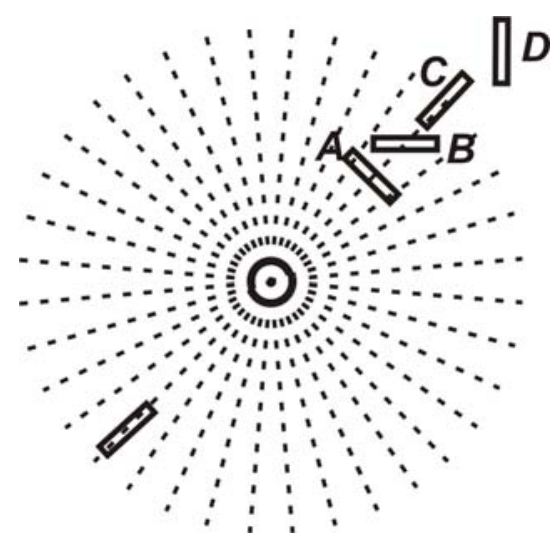

Fig. 10. Plan view of the field on the surface above the transmitter. Receiver positions A-D indicate maximum signal strength $(A)$ to null signal strength $(C)$, which can be used to mark out a null line. Intersections of these null lines mark the Ground Zero point.

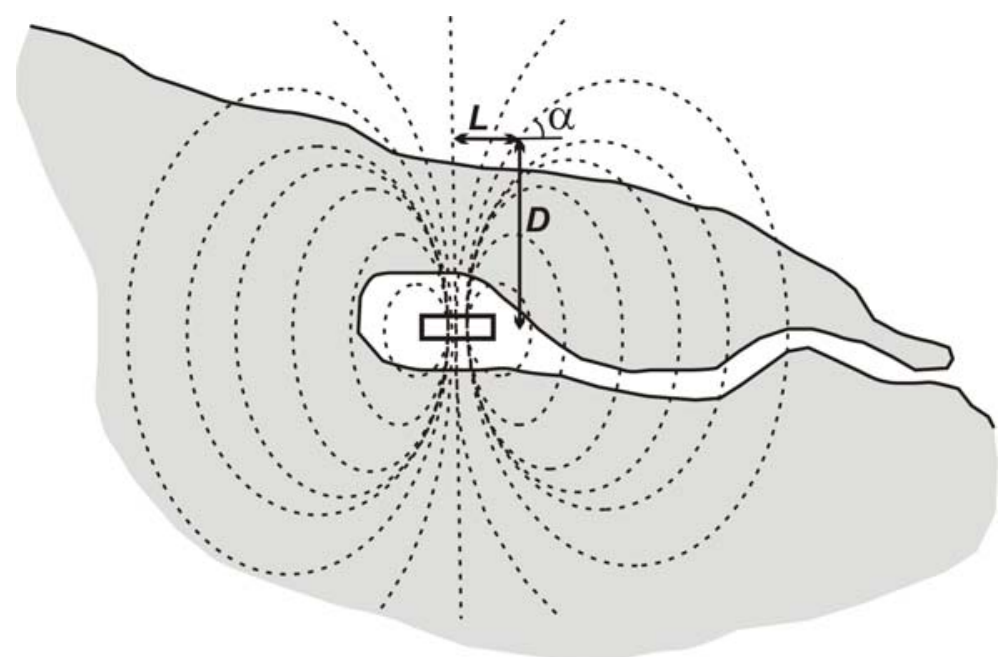

\section{Determination of Depth}

Fig. 11. Determination of depth from radiolocation measurements. $\mathrm{L}$ is distance from Ground Zero and $\alpha$ is the field angle. 


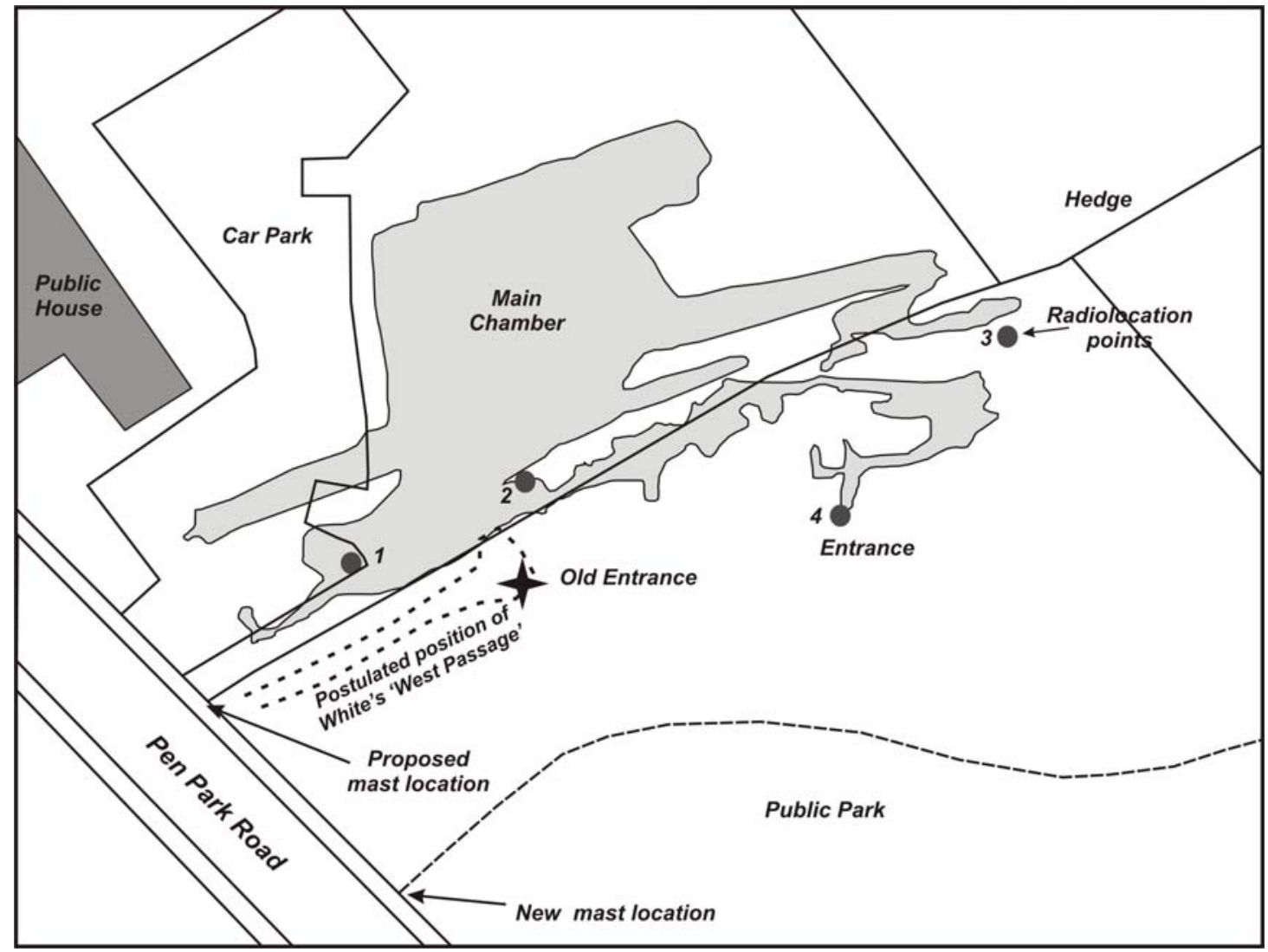

Fig. 12. Plan of Pen Park Hole relative to the surface using the radio-located point on the West Balcony and the Entrance to fix the survey. Black circles mark the radiolocation points. The postulated location of White's 'West Passage' is shown. 